\title{
Ground improvement using waste shell for farm roads and embankments
}

\author{
Siti Hanggita Rachmawati, ${ }^{1,2}$ Zakaria Hossain, ${ }^{1}$ Jim Shiau ${ }^{3}$ \\ ${ }^{1}$ Department of Environmental and Science, Graduate School of Bioresources, Mie University, Tsu, Japan; \\ ${ }^{2}$ Faculty of Agriculture, University of Sriwijaya, South Sumatera, Indonesia; ${ }^{3}$ School of Civil Engineering \\ and Surveying, University of Southern Queensland, Australia
}

\begin{abstract}
The bearing capacity of subgrade soil plays an important role in the performance of agricultural earth structures such as farm roads or earth embankments. It also has a strong link to the budgeting efficiency of those agricultural earth structural projects. One way to improve the subgrade of soil is by using stabilised material in the subgrade layer. Shell husk waste is one of the construction materials that can be used as a substitute for the subgrade layer. The utilisation of shell husk waste has several purposes such as protecting natural aggregate and preventing problems that arise from the untreated abandoned shell husk waste. In this research, shell husk waste was used as farm road subgrade material. To understand the bearing capacity of soil specimens, a series of California bearing ratio (CBR) tests were carried out by using several types of subgrade layers containing different percentages of shell husk in the soil-shell husk mixture. Three types of subgrade layers were used: subgrade upper layer, subgrade bottom layer, and subgrade double layer, containing 0 (control), 10, 20, and 30\% shell husk in soil-shell husk mixture. The experimental results showed that the addition of shell husk in soil leads to improvement in the CBR values of the ground as compared to control specimens. It was further revealed that by increasing the percentage of shell husk in the soil-shell husk mixture, the CBR value was improved significantly. The highest CBR value was achieved by
\end{abstract}

Correspondence: Siti Hanggita Rachmawati, Department of Environmental and Science, Graduate School of Bioresources, Mie University, Tsu, Japan.

E-mail: 515d2s1@m.mie-u.ac.jp

Key words: Agricultural earth structure; soil; shell husk; bearing capacity; subgrade.

Acknowledgements: the authors would like to thank the partnership support given by Mie University, Japan and Sriwijaya University, Indonesia. The assistance provided by Ms. Matsumori during the research period is also much appreciated.

Received for publication: 1 June 2017.

Accepted for publication: 4 September 2017

CCopyright S.H. Rachmawati et al., 2018

Licensee PAGEPress, Italy

Journal of Agricultural Engineering 2018; XLIX:731

doi:10.4081/jae.2018.731

This article is distributed under the terms of the Creative Commons Attribution Noncommercial License (by-nc 4.0) which permits any noncommercial use, distribution, and reproduction in any medium, provided the original author(s) and source are credited. using subgrade upper layer with a 30\% shell husk in soil-shell husk mixture. The results obtained are encouraging with regard to the utilisation of the waste shell husks for improving the bearing capacity of agricultural earth structures such as farm roads and earth embankments.

\section{Introduction}

Earth fill structures play an essential part in agricultural performance (Figure 1). They offer various advantages and can be used in embankments, roads, and public facilities, depending on the purpose of the construction (Figure 2). Those agricultural structures must be stable under all static and dynamic loadings during construction and in service (Hossain, 2013). The subgrade soils are generally defined by their resistance to deformation under load. The strong subgrade soil can reduce the cost of the embankment or road construction. By using strong or treated subgrade, the required thickness of a flexible pavement can be reduced as compared to untreated and weaker subgrades. It will therefore result in a significant cost saving advantage (Choudhary et al., 2010). Removing the soft soil and replacing it with stronger material such as crushed rock or other recycled materials is well known as a technique to improve subgrade soils (Senol et al., 2006; Choudhary et al., 2010). In an investigation carried out in Spain, it was found that the utilisation several types of stabilised materials for low volume roads had a significant on repair costs due to durability (Gallego et al., 2016). There are many types of stabilised materials one of which is recycled material, which has been recently used in subgrade soil to replace traditional earth material for the purpose of environmental sustainability. Sometimes recycled material is inferior compared to traditional earthen materials, but if its performance achieves the required level, it is nevertheless a very competitive material (Basha et al., 2005).

Shell husk has mechanical properties that are suitable to substitute for traditional earthen materials. Previous studies also showed that shell husk is a good source of calcium oxide $(\mathrm{CaO})$ and calcium carbonate $\left(\mathrm{CaCO}_{3}\right)$, which provides the opportunity to reinforce the soil or bind the material construction (Park, 2014; Motamedi et al., 2015). The utilisation of shell husk as recycled material has the aim of resolving several problems such as preservation of limited natural resources, saving disposal costs and environmental conservation. A huge amount of shell husk waste, especially in coastal areas could decrease the sanitation level of the people who live there. Furthermore, unhealthy living can become a trigger for social problems. Besides, budgeting is always a big problem; for example, Japan spent about US\$ 32 million on disposing of shell husk waste and a large investment is required to treat this waste to give it value (Hossain, 2013). In extreme cases, large amounts of shell husk can cause flooding by forming an embankment that blocks water flux. 
In the present investigation, shell husks are used as material in the subgrade layer with the purpose of stabilising the subgrade of soils. The stabilisation of subgrade soil by using shell husk waste is expected to be used in infrastructure projects including those in the rural sector (roads, embankments) that require huge initial investments and after low rate of returns on investment (Satish, 2007). It is noted that shell husk, as an abandoned material, has a very low cost for infrastructure project investment. The performance of the subgrade is evaluated by using the California bearing ratio (CBR), which also becomes a key parameter in this study. The CBR test has been widely used to evaluate the strength of subgrade soils, sub-base, and base course material for the design of the thickness. A high CBR value indicates excellent quality of the material, although other relevant parameters may be necessary to re-confirm the material's performance (Ekeocha and Egesi, 2014).

In this study, three types of subgrade layers were tested in order to understand their performance responses based on CBR values. The types of layers are the upper layer, bottom layer, and combined layers (upper and bottom layers). The layers were cured for seven days. The purpose of this curing process to develop the relationship between the water content and strength (Senol et al., 2006). Three different percentages of shell husk that is 0 (control),
10,20 , and $30 \%$ were adopted for each type of layer. The results for the effects of different percentages of shell embedded at variable depths of soil as a subgrade layer are depicted and a pertinent discussion comparing the results with those of control specimens is presented.

\section{Materials and methods}

\section{Soil}

The soil contains approximately $26 \%$ gravel ( $4.75-19 \mathrm{~mm}), 7 \%$ granule $(2-4.75 \mathrm{~mm}) 13 \%$ coarse sand $(0.85-2 \mathrm{~mm}), 29 \%$ medium sand $(0.25-0.85 \mathrm{~mm}), 10 \%$ fine sand $(0.075-0.25 \mathrm{~mm}), 11 \%$ silt $(0.005-0.075 \mathrm{~mm})$ and $4 \%$ clay $(<0.005 \mathrm{~mm})$. The other physical properties of soil are summarised in Table 1. The particle size distribution curve of this soil can be found elsewhere. The plasticity chart shown in Figure 3 was prepared using the Unified Soil Classification System (USCS), indicating the engineering properties of the soil.
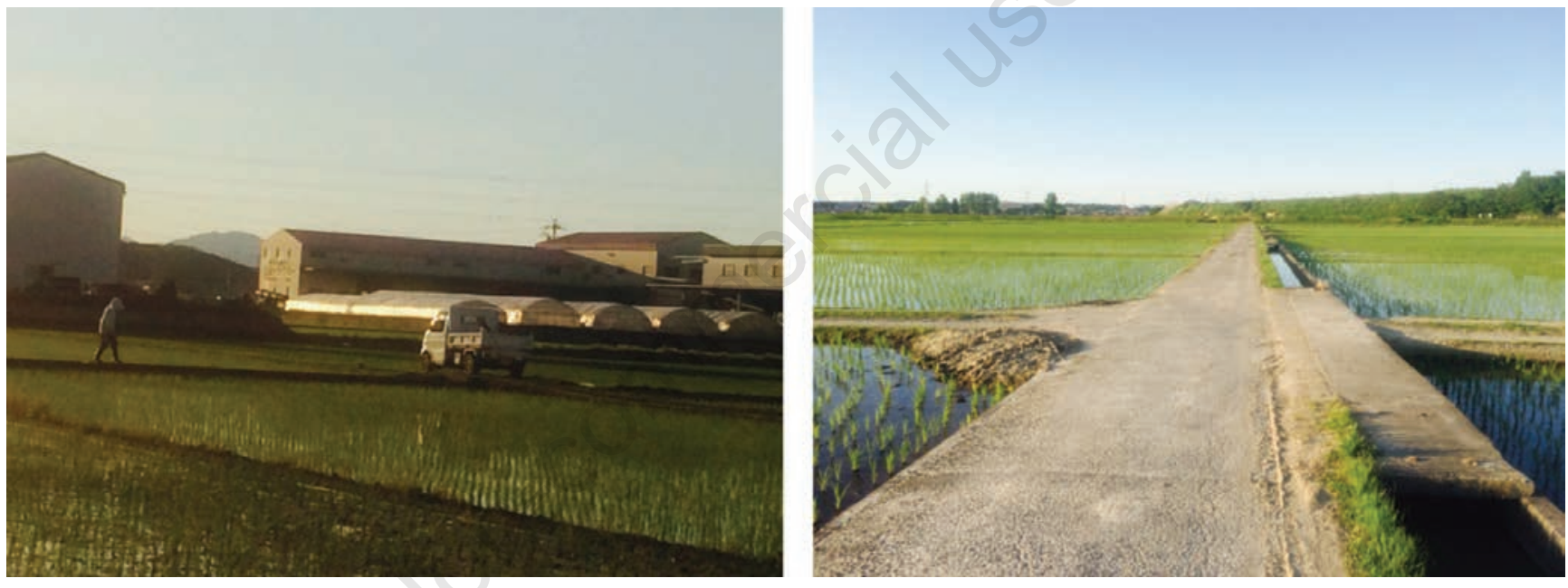

Figure 1. Agricultural structure.
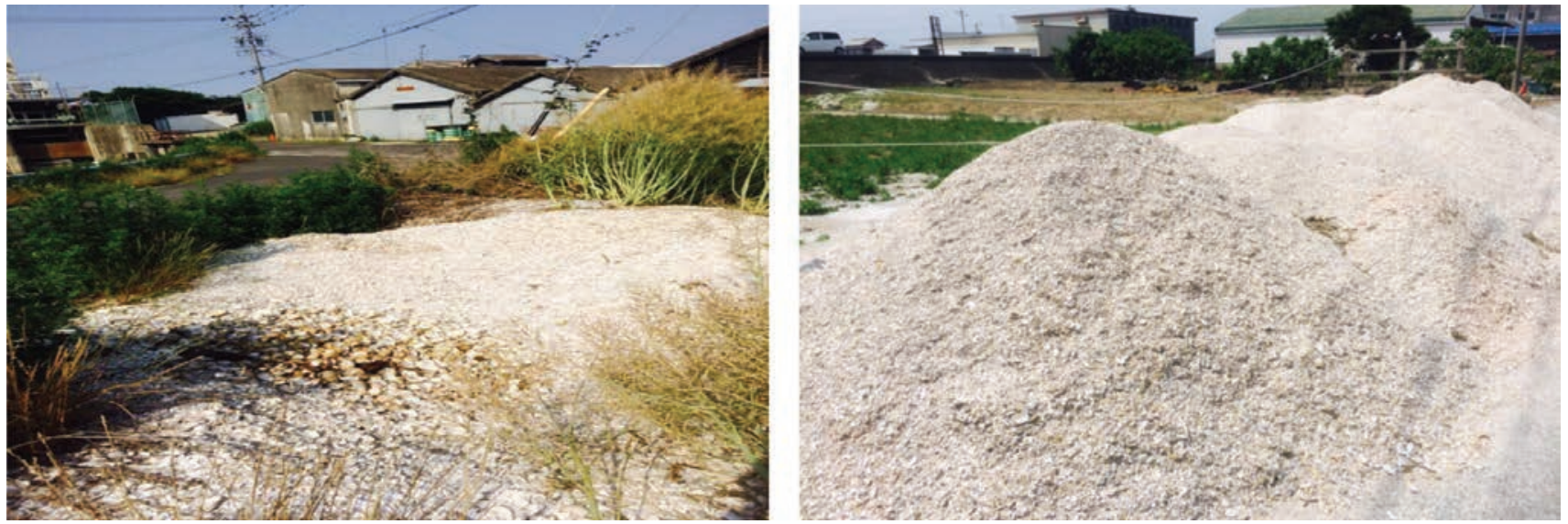

Figure 2. Shell husk waste at Shiratsukacho, Tsu City, Mie Prefecture, Japan. 


\section{Shell husk}

Mactridae shell husk waste was used in this research. The shell husk waste was collected from the seashore close to Mie University, Tsu city, Mie Prefecture, Japan. The shell husks were graded by performing sieve analysis. The fineness modulus and the maximum size of the abandoned shell husks were 4.35 and 4.76 $\mathrm{mm}$, respectively. The shell size distribution curve is shown elsewhere, while Table 2 presents the physical properties of shell husk.

\section{Methodology}

The CBR test is used in this study. It has been widely used all over the world to evaluate the bearing capacity of soils and subgrades since its invention in 1930 by the California Division of highways, USA (Hossain and Sakai, 2008). The CBR is defined as the ratio of the resistance to sinking of a penetration piston having a velocity of $1.27 \mathrm{~mm} / \mathrm{min}(0.05 \mathrm{in} / \mathrm{min})$ into the soil to the resistance shown by a standard crushed rock sample for the same penetration depth (Yildrim and Gunaydin, 2011). The CBR test specimens were prepared in steel molds with an internal diameter of 15 $\mathrm{cm}$ and height of $17.5 \mathrm{~cm}$. To prepare the layers, soil and water ( $12 \%$ of the soil weight) were mixed homogenously. Then the soil was added into the mold after it had been assembled with the bottom plate, spacer disc, and mold extension. The soil was divided

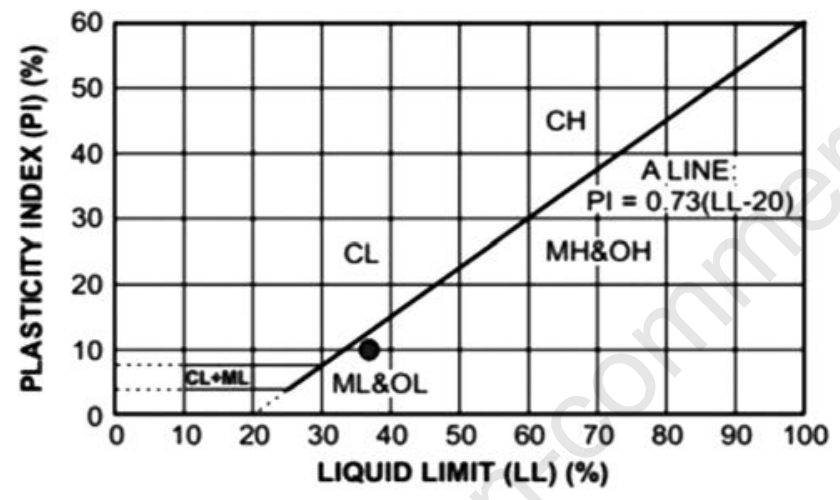

Figure 3. Plasticity chart as per unified soil classification system. into three layers and then tamped 67 times per layer using an automatic rammer. The automatic rammer had diameter of $5.0 \mathrm{~cm}$, mass of $4.5 \mathrm{~kg}$, and falling height of $45.0 \mathrm{~cm}$. The subgrade layers comprised soil mixed with shell husk 10, 20, and $30 \%$ additions of shell husks, respectively. The subgrade layer, shown in Figure 4, was flattened using a small rammer on the surface of the layer, which had been tamped before to achieve a subgrade layer height of $1 \mathrm{~cm}$. The height of the subgrade layers was based on ratio the between field application and laboratory scale, which was 1:5. After the sample had been set up in the mold, it was kept inside a plastic bag to maintain the moisture content for seven days. On the seventh day, the sample was taken out from the plastic and then measured using CBR testing apparatus. Using this apparatus, the loads were recorded up to a penetration depth of $12.5 \mathrm{~mm}$ (JIS-A-

Table 1. Properties of soil.

\begin{tabular}{lc} 
Parameters & Values \\
Dry density $\left(\rho_{d}\right)$ & $1.80 \mathrm{~g} / \mathrm{cm}^{3}$ \\
Optimum water content $\left(W_{\text {opt }}\right)$ & $13.29 \%$ \\
\hline Specific gravity $(\rho s)$ & 2.589 \\
Cohesion $(c)$ & 1.51 \\
\hline Angle of internal friction $(\phi)$ & 23.22 \\
Sand $>75 \mu \mathrm{m}$ & $85.00 \%$ \\
\hline Silt $>5-75 \mu \mathrm{m}$ & $11.00 \%$ \\
Clay $<5 \mu \mathrm{m}$ & $4.00 \%$ \\
\hline Liquid limit & $39.00 \%$ \\
Plastic limit & $26.80 \%$ \\
\hline Plasticity index & $12.20 \%$ \\
\hline
\end{tabular}

Table 2. Physical properties of shell husk Physical properties Values obtained

Water absorption ratio $7.28 \%$ Specific gravity 1.75 Unit weight 1.57
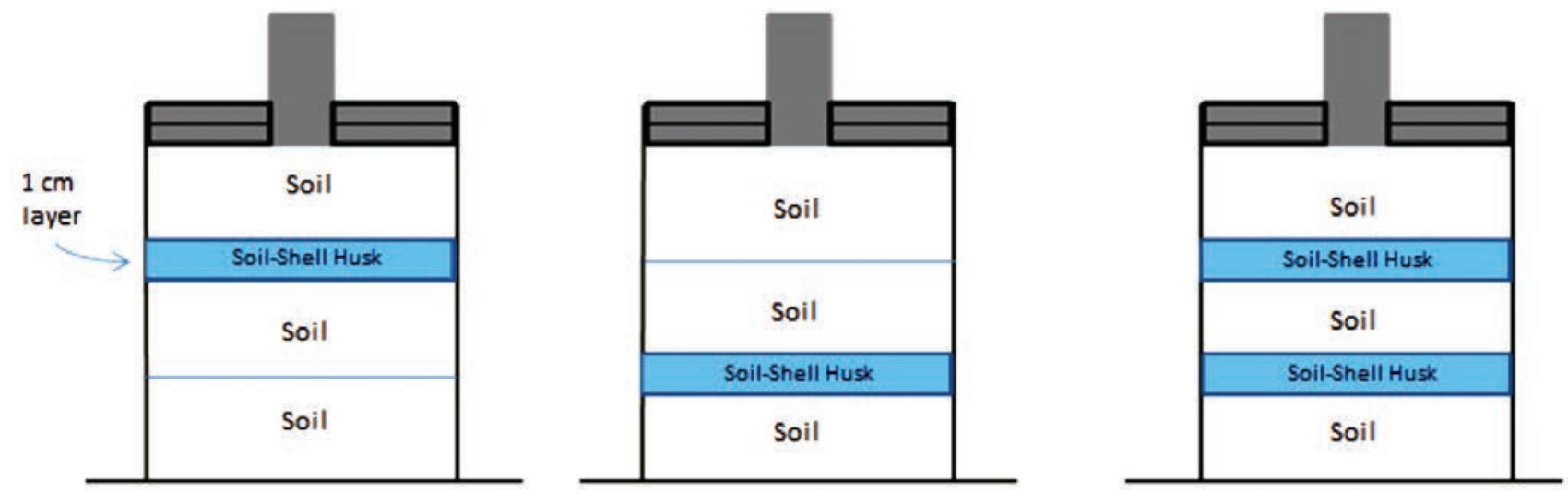

Figure 4. Soil-shell husk layer. 
1211). The CBR value was calculated according to the following equation:

CBR \% $=\underline{\text { Load strength } \times 100}$

Standard load strength

\section{Results and discussion}

\section{Subgrade upper layer}

The load-penetration curves obtained from the CBR tests of the subgrade upper layer containing 10, 20 and, 30\% soil-shell husk mixture are shown in Figure 5. From this figure it can be seen that by increasing the shell husk percentage, the piston load at a given penetration also increases considerably which indicates that the obtained results are reasonable. All curves follow a typical trend of a CBR test.

The calculated CBR values for penetration depths of 5.0 and $2.5 \mathrm{~mm}$ in the upper layer subgrade are given in Table 3. The results show that the CBR values can be improved by increasing the amount of shell husk added to the soil-shell husk mixture. The CBR values for $5.0 \mathrm{~mm}$ penetration for soil mixtures with shell husk contents of 10,20 , and $30 \%$ are $9.88,16.58$, and $29.9 \%$ respectively. The CBR value of the control mixture $(0 \%$ shell husk) in this research is $7.44 \%$. This means that CBR values can approximately four times higher be achieved by increasing the soil-shell husk mixture's shell husk content to $30 \%$ in the subgrade layer compared to the CBR value of the control.

\section{Subgrade bottom layer}

The CBR test results for the subgrade bottom layer containing soil-shell husk mixtures with shell husk contain of 10, 20and, $30 \%$ are shown in Figure 6. It can be seen that the results of the control, and soil-shell husk mixtures with shell husk contain 10, 20, and $30 \%$ all display similar linear trends after penetration depth of $2.5 \mathrm{~mm}$.

The CBR test values for penetration depths of 5.0 and $2.5 \mathrm{~mm}$ in the subgrade bottom layer are also given in Table 3 . It can be observed that the CBR values increase with increasing shell husk percentage in the soil. CBR values for depths of $5.0 \mathrm{~mm}$ produce higher CBR values than those obtained for a depth of $2.5 \mathrm{~mm}$. The CBR values of subgrade bottom layers containing soil-shell husk mixture with 10, 20 and 30 shell husk content are 10.55, 17.09, and $28.14 \%$ respectively.

Table 3. California bearing ratio values of three types subgrade.

\begin{tabular}{lcccc} 
Subgrade layer & CBR & \multicolumn{4}{c}{ Shell percentage(\%) } \\
& standard & 10 & 20 & 30 \\
\multirow{2}{*}{ Upper } & CBR 2.5 & 7.83 & 14.17 & 26.87 \\
& CBR 5.0 & 9.88 & 16.58 & 29.9 \\
\hline \multirow{2}{*}{ Bottom } & CBR 2.5 & 8.96 & 14.93 & 24.63 \\
& CBR 5.0 & 10.55 & 17.09 & 28.14 \\
\hline \multirow{2}{*}{ Double } & CBR 2.5 & 12.69 & 13.43 & 22.39 \\
& CBR 5.0 & 15.08 & 16.08 & 24.37 \\
\hline
\end{tabular}

CBR, California bearing ratio.

\section{Subgrade double layers}

Figure 7 describes the relationship of applied load versus the penetration depth in subgrade double layers containing soil-shell husk mixtures with 10, 20 and, 30\% shell husk. The CBR curves for the double layer subgrade are less pronounced before $2.5 \mathrm{~mm}$ penetration in comparison to the previous two cases in the top and bottom layers. Again, in all cases, the results show similar linear trends after penetration depth of $2.5 \mathrm{~mm}$.

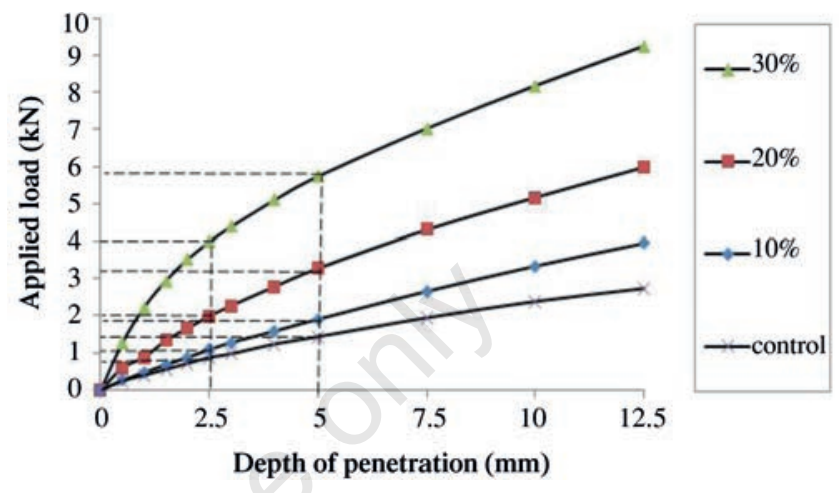

Figure 5. Load penetration curve of subgrade upper layer.

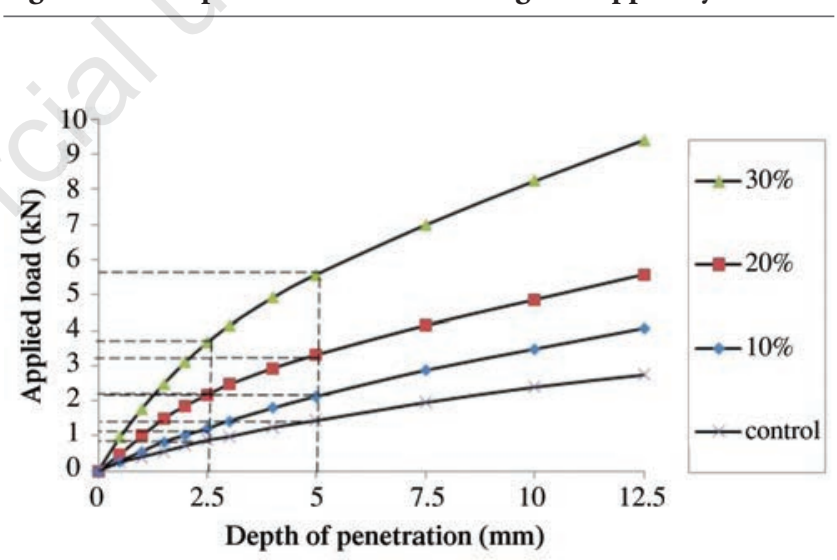

Figure 6. Load penetration curve of subgrade bottom layer.

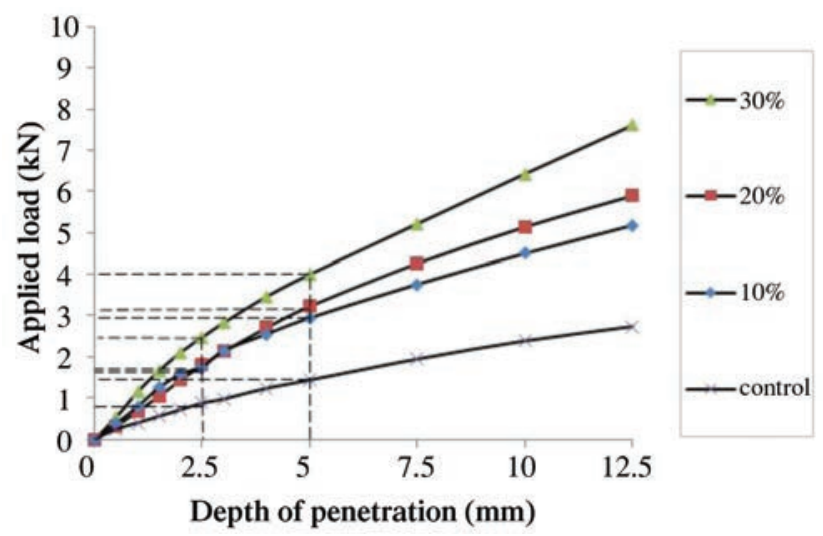

Figure 7. Load penetration curve of subgrade double layers. 
The CBR values for penetration depth of 5.0 and $2.5 \mathrm{~mm}$ penetration are given in Table 3. In comparison to the previous two cases of the top and bottom layers, the current CBR results do not increase proportionally when the shell husk content in the soilshell husk mixtures varies from 10 to $20 \%$. Nevertheless, all the CBR test values show that the penetration depth of $5.0 \mathrm{~mm}$ produces higher CBR values than the penetration depth of $2.5 \mathrm{~mm}$. The CBR values for a penetration depth of $5.0 \mathrm{~mm}$ for subgrade double layers containing soil-shell husk mixtures with shell husk contents of 10, 20 and, 30\% are 15.08, 16.08 and, $24.37 \%$ respectively.

\section{Comparison among the three types of subgrade}

Table 3 summarises the CBR values of the three types of subgrades with various percentages of shell husks. It shows that increasing the amount of shell husk in all three types of subgrade has a significant effect on improving the CBR value. The CBR value of upper layer of subgrade with $10 \%$ shell husk has the lowest CBR value, whilst the subgrade double layer has the highest one. On the other hand with the addition of $20 \%$ shell husk in soilshell husk mixture, the subgrade double layer shows the lowest CBR value and the subgrade bottom layer the highest. Further addition of shell husk in the subgrade layers alters the behaviour of the ground conspicuously. It is observed that the 30\% shell husk mixture in the subgrade upper layer gave the highest CBR value compared to the other two cases, whilst the subgrade double layer showed the lowest CBR value. Overall, for all types of subgrades, the $30 \%$ shell-husk mixture gave the highest CBR value as compared to other shell-husk percentages and the $10 \%$ shell husk mixture gave the lowest value. Interestingly, the increase in the double layer is less than those in the upper and bottom layers, indicating that there is no benefit in using a double layer in constructions with $30 \%$ shell husk.

\section{Conclusions}

Based on the experimental study of the three types of subgrade layers with various soil-shell husk mixtures (10, 20, and 30\% shell husk), it was concluded that the CBR value increases by a factor approximately two to four as the addition of shell husk in the mixture increases from the control $(0 \%)$ to $30 \%$. The highest CBR value was reached by the subgrade upper layer with $30 \%$ shell husk and the lowest CBR was obtained by the subgrade upper layer with $10 \%$ shell husk. It was also interesting to note that the double subgrade layer is not as beneficial as originally expected when compared to a single upper or bottom layer containing $30 \%$ shell husk. This conclusion has certain economic implications for optimising design and construction using soil-shell husk mixtures. It is recommended that more research be done to outline the correlation between CBR values and shear strength parameters.

\section{References}

Basha E.A., Hashim R., Mahmud H.B., Muntohar A.S. 2005. Stabilisation of residual soil with rice husk ash and cement. J. Constr. Build. Mat. 19:448-53.

Choudhary A.K., Jha J.N. Gili K.S. 2010. A Study on CBR behavior of waste plastic strip reinforced soil. Emi. J. Eng. Re. 15:51-7.

Ekeocha N.E., Egesi N. 2014. Evaluation of subgrade soils using California bearing ratio (CBR) in parts of rivers state. J. App. Sci. Env. Man. 18:185-7.

Gallego E., Moya M., Ayuga Tellez E., Garcia A.I., Ayuga F. 2016. The influence of management and construction methods in the repair costs of Spain's low-volume road network. J. Agricult. Eng. 2016;17:537.

Hossain Z. 2013. Waste shell husks concrete: durability, permeability and mechanical properties. Scientific Research. J. Buil. Constr. Plan. Re. 1:61-6.

Hossain Z., Sakai T. 2008. The effectiveness of nominal dosage of ordinary cement on strength and permeability of clayey soil. J. Jpn. Soc. Soil Phys. 110:25-35.

Motamedi S., Shamshirband S., Hashim R., Petkovic D., Roy C. 2015. Estimating unconfined compressive strength of cockle shell-cement-sand mixtures using soft computing methodologies. Eng. Struc. 98:49-58.

Park K., Jun S., Kim D. 2014. Effect of strength enhancement of soil treated with environment-friendly calcium carbonate powder. The Sci. World J. 2014:526491.

Satish P. 2007. Rural infrastructure and growth: an overview. Ind. Jn. Agri. Econ. 62:32-51.

Senol A., Edil T.B., Sazzad Md., Acosta H.A., Benson C.H. 2006. Soft subgrades'stabilisation by using various fly ashes. J. Re. Cons. Re. 46:365-76.

Yildrim B., Gunaydin O. 2011. Estimation of California bearing ratio by using soft computing systems. J. Exp. Sys. App. 38:6381-91. 